\title{
Monoqueima de porcelanas esmaltadas em forno de micro-ondas
}

\section{(One-step microwave sintering of porcelains)}

\author{
J. P. C. Fernandes, R. F. K. Gunnewiek, P. M. Souto, R. H. G. A. Kiminami \\ Laboratório de Desenvolvimento e Processamento de Materiais em Micro-ondas - LaDProM, \\ Departamento de Engenharia de Materiais, Universidade Federal de S. Carlos, Rod. Washington Luiz, km 235, \\ S. Carlos, SP 13565-905 \\ ruth@power.ufscar.br
}

\begin{abstract}
Resumo
A utilização da energia de micro-ondas no processamento de materiais cerâmicos apresenta vantagens quanto ao tempo de processo e homogeneidade microestrutural. Este trabalho tem como objetivo estudar a monoqueima de porcelanas de decoração esmaltada em um substrato de geometria complexa utilizando o aquecimento ultrarrápido híbrido por micro-ondas. As peças foram conformadas por colagem de barbotina e, ainda a verde, esmaltadas por imersão e queimadas pelo processo de monoqueima em forno convencional e em forno de micro-ondas. As peças queimadas por micro-ondas apresentaram características físicas, como aparência da superfície, adesão do esmalte, densidade aparente e resistência mecânica igual ou superior ao processo convencional de queima em apenas 24 min, equivalente a menos de $10 \%$ do tempo utilizado na sinterização convencional.
\end{abstract}

Palavras-chave: porcelana, monoqueima, micro-ondas.

\begin{abstract}
The use of microwave energy in ceramic processing offers advantages such as shorter processing times and high structural homogeneity. The purpose of this work is to produce glazed porcelain samples by microwave hybrid sintering. Glazed porcelain samples with complex geometry were formed by slip casting, green glazed by immersion and subjected to one-step microwave and conventional sintering. The microwave sintered samples presented the same or superior physical characteristics of surface appearance, glass adhesion, apparent density and porosity, and modulus of rupture than the conventionally sintered samples in only 24 min of total sintering time, i.e., less than $10 \%$ of the conventional sintering time.
\end{abstract}

Keywords: one-step sintering, porcelain, microwaves.

\section{INTRODUÇÃO}

Durante 50 anos as micro-ondas foram utilizadas em diversos setores, como comunicação, terapia médica, secagem de madeira, vulcanização de borrachas e na indústria de alimentos. O uso de micro-ondas na síntese e processamento de cerâmicas, polímeros, metais, vidro e compósitos vem ganhando muito destaque devido à eficiência e rapidez do processo, obtendo-se produtos equivalentes ou superiores aos obtidos por técnica convencional aliado à economia de tempo e consequentemente de energia [1]. O grupo de pesquisas do LaDProM/DEMa/UFSCar foi um dos pioneiros no país a estudar o processamento de cerâmicas utilizando energia de micro-ondas, tendo obtido vários sucessos na síntese de nanomateriais e compósitos, bem como na sinterização de cerâmicas [2-7] e mais recentemente na queima de porcelanas esmaltadas.

A preocupação em redução de gastos energéticos cada vez mais tem pressionado o setor de processamento cerâmico a desenvolver e utilizar técnicas rápidas e eficientes na produção de cerâmicas de alta qualidade. Cerâmicas convencionais esmaltadas têm sido obtidas pelos processos de biqueima e monoqueima. Na biqueima as peças cerâmicas são submetidas a dois tratamentos térmicos distintos. O suporte cerâmico é sinterizado e em seguida passa pela esmaltação; ocorre novamente a sinterização em menor temperatura para não comprometer o corpo cerâmico, estabilizando os esmaltes e as decorações aplicadas no suporte. Na monoqueima são sinterizados tanto o suporte cerâmico como o vidrado em um único processo. Nesse tratamento térmico ocorrem a consolidação do suporte e a estabilização do vidrado simultaneamente, proporcionando melhor interação e melhora da resistência da peça. Utiliza-se somente um forno para o processo designado por monoqueima, diminuindo os custos econômicos da fabricação dos produtos cerâmicos, comparados com a biqueima. Normalmente, a monoqueimadas porcelanas é feita em fornos contínuos ou intermitentes em tempos de processamento entre 5 e $8 \mathrm{~h}$, dependendo da composição, geometria e dimensões da peça $[8,9]$. No entanto, o processo não é tão simples, já que existe certa dificuldade no processamento simultâneo do vidrado e substrato, devido às suas distintas características cinéticas durante $\mathrm{o}$ processamento. $\mathrm{O}$ substrato base requer temperaturas 
mais elevadas e tempos maiores de processamento para atingir as propriedades desejadas de resistência mecânica e porosidade, enquanto que o esmalte requer temperatura e tempos menores de processamento. A dificuldade é agravada quando produtos de geometria complexa, sendo o substrato uma porcelana, devem ser esmaltados e processados por monoqueima. Defeitos podem ocorrer durante o processamento, tanto no substrato base (peça frágil ou pouco porosa, dificultando a adesão do vidrado) como no vidrado (bolhas, picados, fissuramento e enrolamento), e evoluem principalmente durante a sinterização, devido à temperatura e tempo de processamento inadequado [8]. $\mathrm{O}$ controle da temperatura do forno é mister quando o objetivo é obter peças perfeitas e diminuir gradientes no forno e na própria peça. Porém, o processamento convencional ainda dificulta manter a homogeneidade de temperatura, além de dispendioso em se falando do aquecimento da peça. Uma alternativa é o processamento de monoqueima de porcelanas por micro-ondas, visando ainda a redução do tempo de processamento sem comprometer as propriedades finais das peças. Na queima por micro-ondas a transferência de calor dá-se de forma homogênea e praticamente instantânea, dependendo basicamente apenas da frequência da radiação, da temperatura e da permissividade elétrica do material. Normalmente, as cerâmicas a temperaturas baixas são transparentes às micro-ondas, absorvendo-as apenas quando se atinge certa temperatura crítica. Esse problema pode ser contornado pela sinterização híbrida, em que um elemento de aquecimento (por resistência ou susceptor) aquece previamente o material. Os processos difusionais ocorrem de maneira acelerada quando o material é processado por micro-ondas [10, 11].

As porcelanas são sistemas complexos devido às interações entre seus multicomponentes [12], tais como reações, mudança de fase, formação de fase líquida. Embora o convencional seja bem estudado, o processamento de porcelanas e esmaltes por micro-ondas ainda carece de publicações. Pesquisadores foram bem sucedidos em processar porcelanas das mais diversas (dentárias, sanitária e elétrica) por micro-ondas em tempos curtos de 6 a $10 \mathrm{~min}$, obtendo-se corpos com excelentes propriedades físicas [6]. Houve também sucesso ao processar por micro-ondas um vidrado para recobrimento de liga metálica [13]. Apesar do crescente interesse no processamento de cerâmicas por micro-ondas, poucos estudos se encontram a respeito da sinterização de cerâmicas tradicionais e não há publicações sobre monoqueima de porcelanas esmaltadas por microondas. Diante disso, o objetivo deste trabalho foi estudar a monoqueima de porcelanas esmaltadas em um substrato de geometria complexa (coelho) utilizando o aquecimento ultrarrápido híbrido por micro-ondas. A monoqueima convencional também foi avaliada visando uma comparação com os resultados obtidos por micro-ondas.

\section{MATERIAIS E MÉTODOS}

A massa utilizada neste estudo foi fornecida por uma
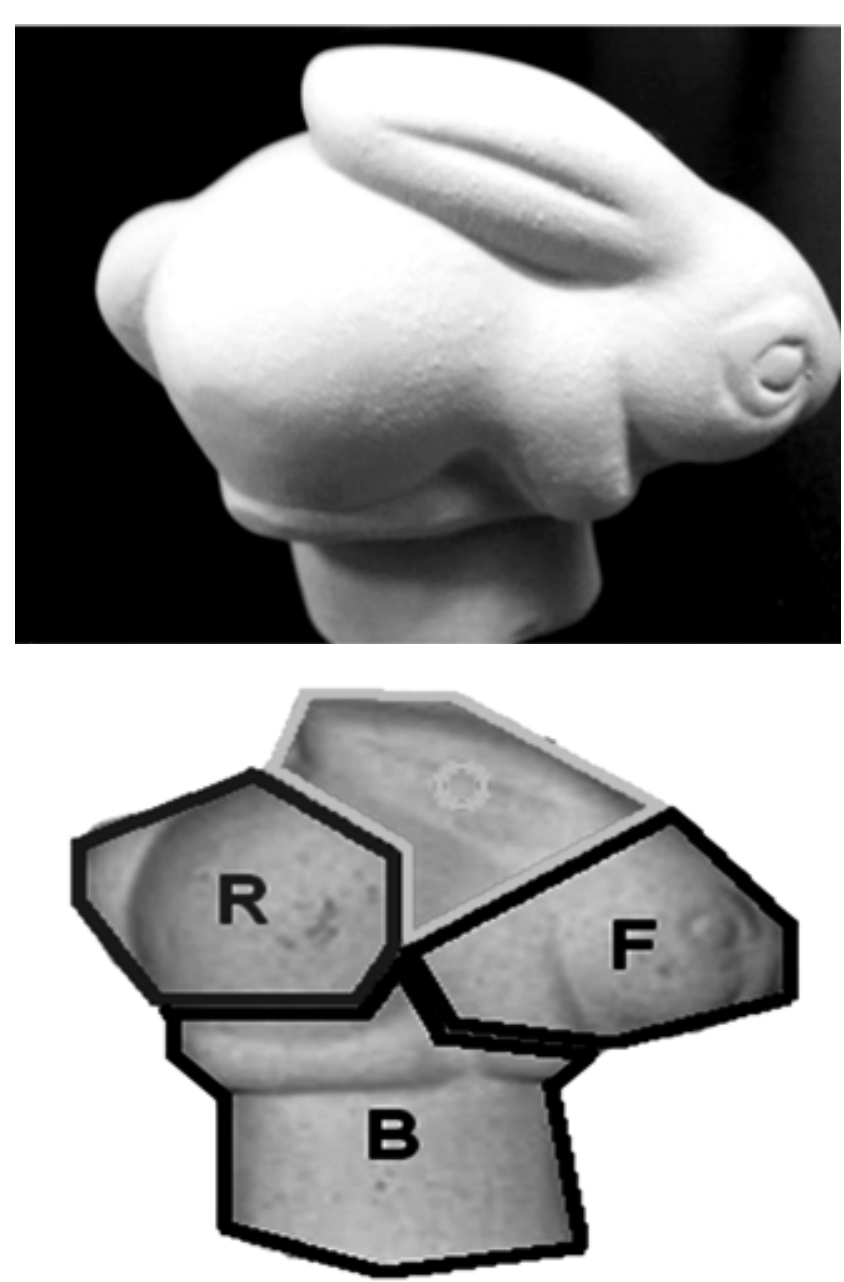

Figura 1: Acima - peça de geometria complexa a verde; abaixo classificação segundo local na peça. $\mathrm{R}=\mathrm{Rabo}, \mathrm{O}=$ Orelha, $\mathrm{F}=$ Focinho e B = Base.

[Figure 1: Top - green complex geometry sample; bottom - sample parts classification: $R=$ Tail, $O=$ Ear, $F=$ Nose and $B=$ Base.]

empresa de cerâmica de Porto Ferreira, SP. Essa massa foi conformada por colagem de barbotina em moldes de gesso. As peças de geometria complexa, no formato de coelhos com detalhes a serem avaliados após a queima, apresentavam tamanho de $\sim 6,5 \times 2,5 \times 6,0 \mathrm{~cm}^{3}$. As peças foram previamente secas em estufa, esmaltadas ainda a verde por imersão e novamente secas, conforme realizadas na empresa. $\mathrm{O}$ aspecto da peça a verde pode ser visto na Fig. 1. Foram também conformadas por colagem de barbotina, com a mesma massa, amostras em forma de barras de dimensões $6 \times 50 \times 13 \mathrm{~mm}^{3}$ para caracterização quanto à resistência mecânica.

As peças foram sinterizadas em forno de micro-ondas a 2,45 GHz e 2 kW (CoberElectronics, MS6K). Para estudo preliminar das condições de queima as amostras sem esmalte foram sinterizadas em micro-ondas de 900 a $1200{ }^{\circ} \mathrm{C}$ com incrementos de $100^{\circ} \mathrm{C}$, em taxas de aquecimento de $50{ }^{\circ} \mathrm{C} /$ min até $1000^{\circ} \mathrm{C}$ e reduzidas para $25^{\circ} \mathrm{C} / \mathrm{min}$ até temperaturas superiores, e tempo de patamar $8 \mathrm{~min}$. Convencionalmente, as amostras foram sinterizadas em forno Lindberg Blue 
M sob taxa de aquecimento $3{ }^{\circ} \mathrm{C} / \mathrm{min}$ e patamar $120 \mathrm{~min}$ a $900,1000,1100$ e $1200{ }^{\circ} \mathrm{C}$. Após a queima, as amostras de geometria complexa foram fraturadas e classificadas segundo o local da peça, (R) Rabo, (O) Orelha, (F) Focinho e (B) Base, como apresentado na Fig. 1b. Essa classificação foi necessária para avaliar a uniformidade da queima e propriedades após sinterização convencional e por microondas. As peças obtidas, (R) Rabo, (O) Orelha, (F) Focinho e (B) Base, foram então pesadas e fervidas por $2 \mathrm{~h}$, resfriadas e pesadas as massas imersa e úmida, calculando-se assim a porosidade e densidade aparente segundo método baseado no princípio de Arquimedes. Amostras foram preparadas para análise microestrutural por microscopia eletrônica de varredura (Phillips XL30-FEG): secadas em estufa, embutidas em resina polimérica, polidas e recobertas com fina camada de ouro.

Barras sinterizadas nas mesmas condições das peças de geometria complexa foram caracterizadas mecanicamente por ensaio de flexão em 3 pontos (Hounsfield Tensometer), segundo a norma ASTM C674-88.

A partir da análise dos resultados obtidos, foram feitos processos de monoqueima em forno convencional e em forno de micro-ondas a $1000{ }^{\circ} \mathrm{C}$ com patamares de 15 e 4 min, respectivamente. A diminuição do tempo de patamar foi necessária pela adição do esmalte. Foram analisados os aspectos visuais do esmalte e a interface esmalte/suporte por microscopia eletrônica de varredura.

\section{RESULTADOS E DISCUSSÃO}

As Figs. 2 e 3 apresentam a densidade e porosidade aparente das peças obtidas, (R) Rabo, (O) Orelha, (F) Focinho e (B) Base. A sinterização por micro-ondas possibilitou a obtenção de peças com valores equivalentes de densidade e porosidade aparente, tomando-se a média das partes R, F, O e B para cada condição, com incremento modesto de $6,5 \%$ na densidade aparente e decréscimo de $10 \%$ na porosidade, como podem ser vistos nas Figs. 2 e 3 , em patamares de apenas $7 \%$ do tempo utilizado na queima

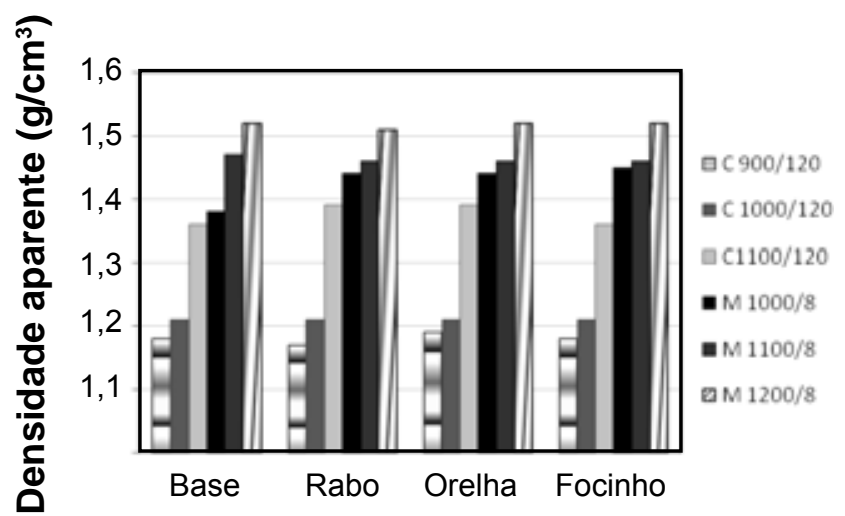

Figura 2: Densidade aparente das partes da peça para cada condição de sinterização: convencional (C) e por micro-ondas (M).

[Figure 2: Apparent density of sample parts for each sintering condition: conventional (C) and microwave (M).] convencional. Valores equivalentes de densidade aparente já haviam sido obtidos para porcelanas, sem esmalte, processadas em forno convencional e ultra rapidamente em micro-ondas, confirmando a eficiência do processamento por micro-ondas [3].

Embora a geometria da peça seja complexa, a sinterização por micro-ondas possibilitou a obtenção de peças homogêneas em qualquer condição de queima, analisada em cada uma das quatro partes da peça, apresentando um desvio inferior a $1 \%$ da densidade média e da porosidade média.

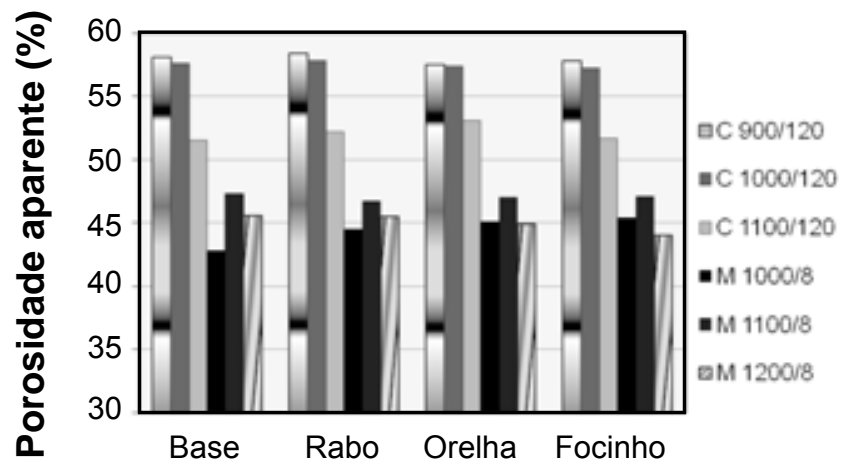

Figura 3: Porosidade aparente das partes da peça para cada condição de sinterização: convencional (C) e por micro-ondas (M). [Figure 3: Apparent porosity of sample parts for each sintering condition: conventional $(C)$ and microwave $(M)$.

As micrografias obtidas por microscopia eletrônica de varredura dos substratos sinterizados convencionalmente a 900,1000 e $1100{ }^{\circ} \mathrm{C}$ por 120 min e por micro-ondas a 1000 , 1100 e $1200{ }^{\circ} \mathrm{C}$ por 8 min podem ser vistas nas Figs. 4a a 4 f. As imagens obtidas no microscópio eletrônico de varredura evidenciam a evolução de microestruturas homogêneas em todas as condições de sinterização. É possível verificar em ambas as condições de sinterização, por micro-ondas e convencionalmente, a formação de fase líquida e diminuição dos poros com o incremento na temperatura, bem como a presença de grãos de quartzo em qualquer temperatura. Muito embora o tempo de processamento seja $90 \%$ maior na sinterização convencional, é evidente a presença de maior quantidade de fase vítrea nas amostras sinterizadas por micro-ondas do que nas sinterizadas convencionalmente, corroborando os dados de porosidade aparente da Fig. 3.

Dentre as principais decorrências da diminuição da porosidade está o aumento da resistência mecânica. A Fig. 5 apresenta as curvas de tensão de ruptura em função da temperatura para as barras conformadas por colagem de barbotina e sinterizadas em micro-ondas e convencionalmente. A peça sinterizada a $900{ }^{\circ} \mathrm{C}$ por microondas não pôde ser ensaiada por ser muito frágil. As peças sinterizadas a 1000 e $1100{ }^{\circ} \mathrm{C}$ apresentam similaridade quanto às suas tensões de ruptura em ambos os processos.

Foram reportados resultados semelhantes aos relatados acima, em que a resistência mecânica foi equivalente em porcelanas dentárias sinterizadas por micro-ondas ou 

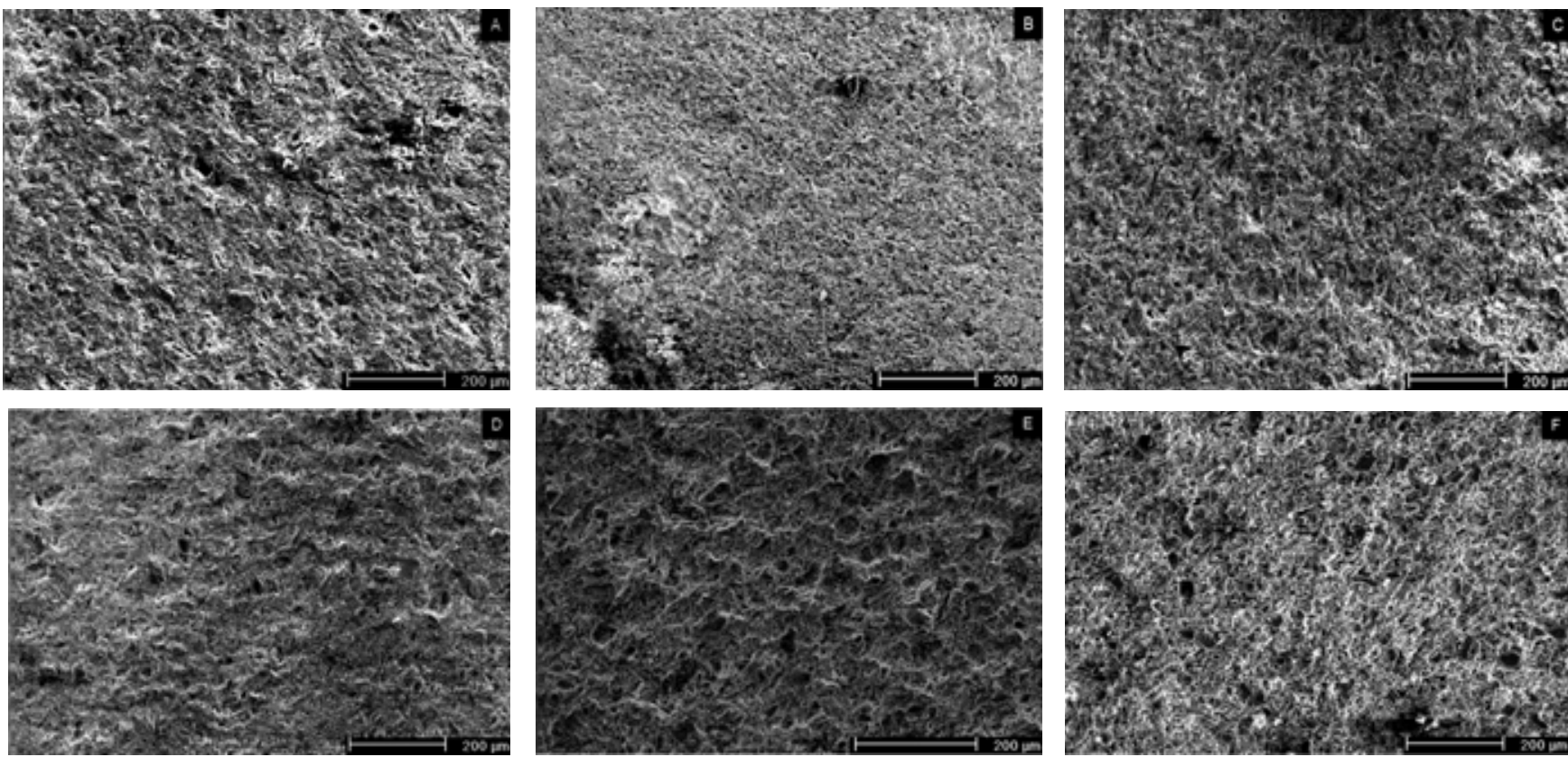

Figura 4: Micrografias obtidas em microscópio eletrônico de varredura das peças sinterizados convencionalmente por 120 min a: a) $900{ }^{\circ} \mathrm{C}$, b) $1000{ }^{\circ} \mathrm{C}$ e c) $1100{ }^{\circ} \mathrm{C}$, e por micro-ondas a: d) $1000^{\circ} \mathrm{C}$, e) $1100{ }^{\circ} \mathrm{C}$, e f) $1200^{\circ} \mathrm{C}$ por $8 \mathrm{~min}$.

[Figure 4: SEM micrographs of samples sintered conventionally by 120 min holding time at: a) $900{ }^{\circ} \mathrm{C}, \mathrm{b}$ ) $1000^{\circ} \mathrm{C}$ and c) $1100{ }^{\circ} \mathrm{C}$, and microwave sintering by 8 min at: d) $1000{ }^{\circ} \mathrm{C}$, e) $1100{ }^{\circ} \mathrm{C}$ and f) $1200^{\circ} \mathrm{C}$.]

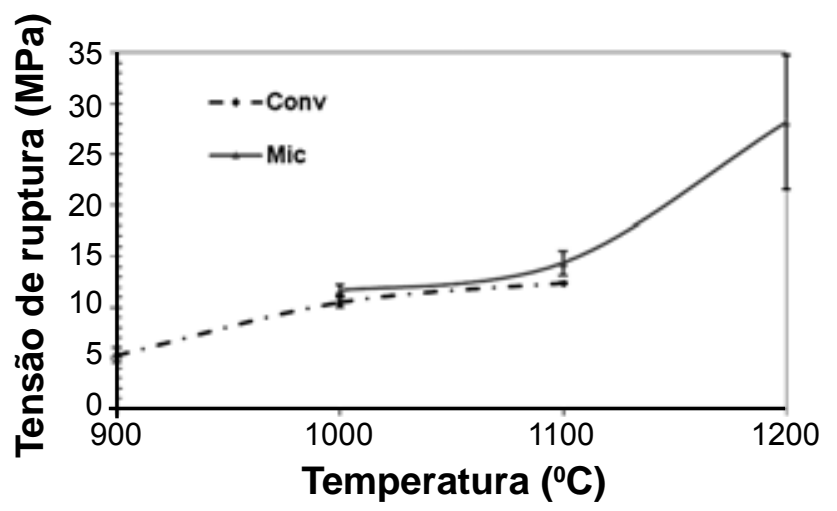

Figura 5: Tensão de ruptura para cada temperatura de sinterização convencional e por micro-ondas.

[Figure 5: Flexural strength for each sintering condition conventional and microwave.]

convencionalmente [14]. Pelo processo de queima em microondas, foi possível obter peças com resistência mecânica de aproximadamente $15 \mathrm{MPa}$ a $1100{ }^{\circ} \mathrm{C}$, equivalente ao processo convencional. Foram produzidas amostras com resistência de $25 \mathrm{MPa}$ sinterizadas a $1200{ }^{\circ} \mathrm{C}$ por $8 \mathrm{~min}$ a uma taxa de aquecimento de $50{ }^{\circ} \mathrm{C} / \mathrm{min}$ em micro-ondas. As peças sinterizadas por micro-ondas a $900{ }^{\circ} \mathrm{C}$ por 8 min não obtiveram boa resistência mecânica, sendo muito frágeis, ao passo que as sinterizadas convencionalmente a $1200{ }^{\circ} \mathrm{C}$ por 120 min desenvolveram resistência mecânica muito elevada. Essa condição de queima foi excessiva, não possibilitando acoplamento esmalte/substrato, além de obtenção de muitas peças deformadas. Foi reportado o mesmo valor de resistência mecânica para porcelanas sinterizadas convencionalmente a $1200{ }^{\circ} \mathrm{C}$ por $30 \mathrm{~min}$ e taxa de aquecimento $2,5^{\circ} \mathrm{C} / \mathrm{min}$ [15]. Não foi observado o fenômeno de 'thermal runaway' em nenhuma das peças, e a redução da taxa de aquecimento no micro-ondas para temperaturas acima de $1000^{\circ} \mathrm{C}$ se mostrou efetiva. Embora o tempo de sinterização em micro-ondas seja curto, incluindo o patamar e as taxas elevadas de aquecimento, é possível observar na Fig. 3 a diminuição da porosidade nas peças sinterizadas em micro-ondas em comparação às sinterizadas convencionalmente. Uma das causas da diminuição de porosidade em porcelanas é o fechamento de poros pela evolução de fase vítrea, que aparentemente foi melhorada com a utilização de micro-ondas. Além disso, a diminuição da porosidade do substrato deveria ter influenciado negativamente no acoplamento esmalte/substrato, porém as peças processadas por monoqueima em micro-ondas a $1000{ }^{\circ} \mathrm{C}$ por 4 min apresentaram superfície com melhor acabamento, mais brilhante e completamente lisas, do que as sinterizadas convencionalmente na mesma temperatura, com patamar de 15 min, como pode ser visto na Fig. 6 .

No processamento de vidrado duro para recobrimento metálico, foi verificado o mesmo efeito de superfície lisa quando processado por micro-ondas em comparação à superfície mais rugosa quando processado convencionalmente [13]. O aparecimento de pequenas bolhas em regiões críticas, em que há acúmulo de esmalte durante a aplicação, pôde ser observado em ambas as condições de queima [8]. É importante salientar que não foi aplicada camada intermediária de engobe nas peças do presente trabalho, cuja principal função, além da estética, é proporcionar melhor acoplamento entre o substrato e o 

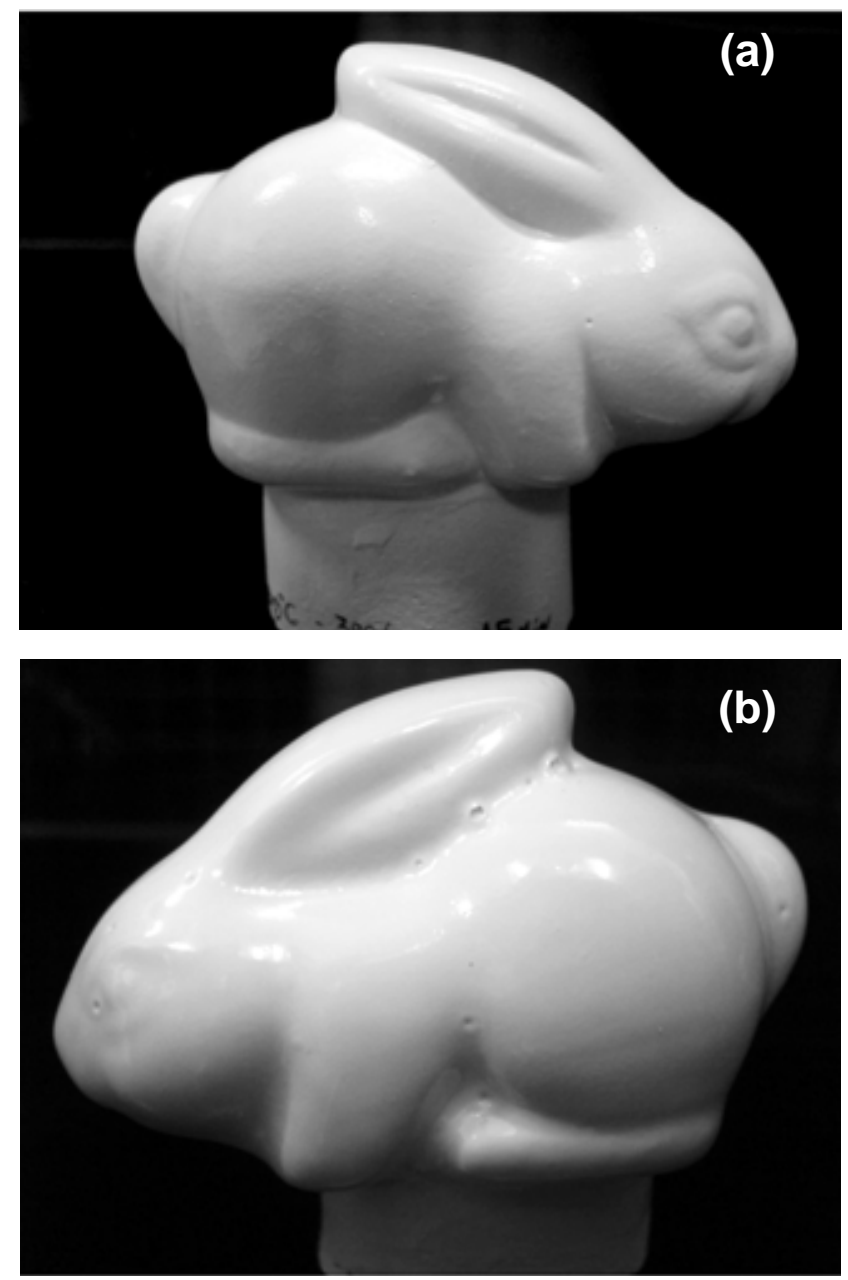

Figura 6: Peças esmaltadas sinterizadas via monoqueima: a) convencional $1000^{\circ} \mathrm{C} / 15 \mathrm{~min}$ e b) por micro-ondas a $1000^{\circ} \mathrm{C} / 4 \mathrm{~min}$. [Figure 6: One-step sintered glazed samples: a) conventional at $1000^{\circ} \mathrm{C} / 15 \mathrm{~min}$ and b) microwave at $1000^{\circ} \mathrm{C} / 4 \mathrm{~min}$.]

esmalte $[8,16]$. A interface esmalte/substrato em ambos os casos é muito parecida, como pode ser observado nas Figs. $7 \mathrm{a}$ e $7 \mathrm{~b}$; o substrato poroso possibilitou o perfeito acoplamento nas peças sinterizadas a $1000^{\circ} \mathrm{C}$ por $4 \mathrm{~min}$, em micro-ondas e por 15 min convencionalmente. $\mathrm{O}$ esmalte apresenta algumas bolhas microscópicas em ambas peças e tais bolhas não influenciaram as características superficiais da peça sinterizada em micro-ondas, podendo ser descartado esse fator do pior acabamento da peça sinterizada convencionalmente. A resistência mecânica alcançada pelas peças queimadas por monoqueima em micro-ondas e em forno convencional foi de aproximadamente 3,5 MPa. A menor resistência mecânica apresentada reflete a diminuição do tempo de sinterização pela diminuição do patamar de queima; contudo, foi possível obter peças com resistência mecânica equivalente e substancial diminuição do tempo de processo por micro-ondas.

Assim, ficou evidente que a monoqueima de porcelanas esmaltadas por micro-ondas é um processo viável e apresenta diversas vantagens frente ao processamento convencional, que inclui diminuição de tempo de processamento total de
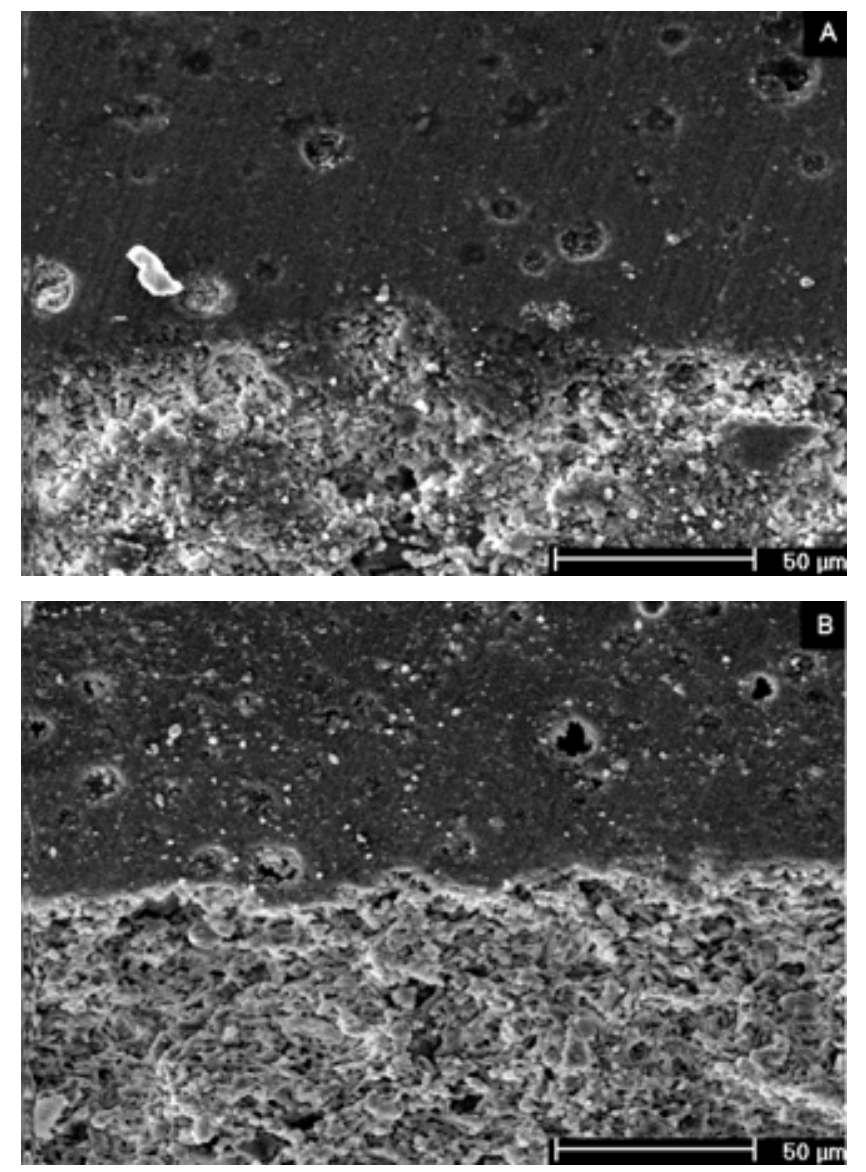

Figura 7: Micrografias obtidas em microscópio eletrônico de varredura da interface esmalte (superior)/substrato (inferior) do processo de monoqueima a) convencional a $1000{ }^{\circ} \mathrm{C} / 15 \mathrm{~min}$ e b) micro-ondas a $1000{ }^{\circ} \mathrm{C} / 4 \mathrm{~min}$.

[Figure 7: SEM micrographs of the interface glass (top)/basis (bottom) by one-step sintering: a) conventional at $1000^{\circ} \mathrm{C} / 15 \mathrm{~min}$ an b) microwave at $1000^{\circ} \mathrm{C} / 4 \mathrm{~min}$.]

5 a $8 \mathrm{~h}$ para apenas $24 \mathrm{~min}$, totalizando menos de $10 \%$ do tempo de queima, com elevadas taxas de aquecimento de $50{ }^{\circ} \mathrm{C} / \mathrm{min}$, obtendo-se produtos com acabamento excelente, acoplamento esmalte/substrato perfeito, não ocorrência de deformação causada por gradientes térmicos durante a queima e com resistência mecânica equivalente às peças sinterizadas convencionalmente. Foi possível processar peças de porcelana esmaltadas com geometria complexa com características homogêneas e acabamento superior ao processo convencional, com o diferencial da redução substancial do tempo de processamento, tornando-se uma alternativa inovadora para as indústrias de porcelana. Os resultados obtidos evidenciam a eficiência e viabilidade do processamento por micro-ondas de cerâmicas convencionais de alta qualidade.

\section{CONCLUSÕES}

O presente trabalho mostrou a viabilidade da monoqueima por micro-ondas em porcelanas esmaltadas com geometria complexa em tempo total de queima inferior a $10 \%$ do tempo 
de sinterização convencional, possibilitando economia de tempo e, consequentemente, energia, obtendo-se peças de porcelana de excelente qualidade. Foram obtidas peças homogêneas, com densidade aparente superior e menor porosidade que as peças obtidas por queima convencional. A formação de fase vítrea foi mais acentuada na queima por micro-ondas, sem afetar a adesão esmalte/substrato. As peças sinterizadas por micro-ondas apresentaram superfície lisa e brilhante, enquanto as sinterizadas convencionalmente mostraram-se opacas e de aparência rugosa. As peças sinterizadas por micro-ondas apresentaram resistência mecânica equivalente às das sinterizadas convencionalmente.

\section{AGRADECIMENTOS}

Ao $\mathrm{CNPq}$ pelas bolsas concedidas e à FAPESP pelo auxílio financeiro (Procs. 07/59564-0 e 08/04025-0).

\section{REFERÊNCIAS}

[1] M. Oghbaei, O. Mirzaee, J. Alloys Compnd. 494 (2010) 175.

[2] E. Fagury-Neto, R. H. G. A. Kiminami, Ceram. Int. 27(2001) 815.

[3] R. R. Menezes, P. M. Souto, R. H. G. A. Kiminami, J. Mater. Process. Technol. 190 (2008) 223.

[4] R. R. Menezes, R. H. G. A. Kiminami, J. Mater. Process.
Technol. 203 (2008) 513.

[5] R. R. Menezes, P. M. Souto, R. H. G. A. Kiminami, Cerâmica 53, 235 (2007) 1.

[6] R. R. Menezes, P. M. Souto, R. H. G. A. Kiminami, in: A. Lakshmanan, Ed., "Sintering of ceramics - New emerging techniques", InTech (2012) 3.

[7] R. F. K. Gunnewiek, R. H. G. A. Kiminami, Mater. Sci. Forum 691 (2011) 65.

[8] H. J. Oliveira, J. A. Labrincha, Cerâmica Ind. 7 (2002) 28.

[9] E. Kivitz, B. Palm, J. G. Heinrich, J. Blumm, G. Kolb, J. Eur. Ceram. Soc. 29 (2009) 2691.

[10] D. K. Agrawal, Curr. Opin. Solid State Mater. Sci. 3, 5 (1998) 480.

[11] D. E. Clark, W. H.Sutton, Annu. Rev. Mater. Sci. 26 (1996) 299.

[12] W. M. Carty, U. Senapati, J. Am. Ceram. Soc. 81 (1998) 3.

[13] S. Das, A. K. Mukhopadhyay, S. Datta, G. C. Das, D. Basu, J. Eur. Ceram. Soc. 28 (2008) 729.

[14] S. Prasad, E. A. Monaco Jr, H. Kim, E. L. Davis, J. D. Brewer, J. Prosthet. Dent. 101 (2009) 20.

[15] S. R. Bragança, C. P. Bergman, Cerâmica 50, 316 (2004) 291.

[16] S. Pracidelli, Cerâmica Ind. 13 (2008) 8.

[17] T. Santos, L. C. Costa, L. Hennertier, M. A.Valente, J. Monteiro, J. Sousa, Appl. Therm. Eng. 50 (2013) 677.

(Rec. 03/04/2013, Ac. 26/05/2013) 